\section{TÀI LIÊU THAM KHẢO}

1. Đinh Thị Kim Dung (2003), "Nghiên cứu rối loan Lipoprotein huyết thanh ở bệnh nhân suy thận mạn" ${ }^{\prime}$ Luận án tiến sĩ.

2. Nguyến Thị Phòng (2007), "Nghiên cứu rối loạn lipid máu ở bệnh nhân suy thân mạn giai đoạn III - IV". Luânn án chuyên khoa cấp 2, Trường đại học y dước Huế

3. Võ Tam và cộng sự (2011), Khảo sát rối loạn lipid máu ở bênh nhẩn suy thân giai đoan cuối lọc màng bụng", Trường đại học y dược Huể.

4. Ivana Mikolasevic, Marta Zutelija, Vojko mavrinac (2017), Dyslipidemia in patients with chronic kidney disease: etiology and management, Int J Nephrol Renovasc Dis, 10; 35-45.

5. KDIGO (2012), KDIGO 2012 Clinical practice guideline for the Evaluation and management of chronic kidney disease, Kidney International supplements.

6. Joana Mesquita, Ana Valera (2010), Dyslipidemia in renal disease: Causes, consequences and treatment, Endocinologia $Y$ Nutricion, 57(9): 440-448.

7. Sarnak MJ, Levey AS, Schoolwerth AC (2003), Kidney disease as a risk factor for development of cardiovascular disease, Hypertesion, 42(5): 1050-1065.

\title{
ĐÁNH GIÁ KẾT QUẢ PHẪU THUÂTT CỦA UNG THƯ ỐNG TIÊU HÓA KHÔNG THUỘC BIỂU MÔ TẠI BÊ̂NH VIỆN HỮU NGHỊ VIỆT ĐỨC TRONG 10 NĂM
}

\section{TÓM TẮT}

Mục tiêu: Đánh giá kết quả điều trị phẫu thuât của ung thư ống tiếu hóa không thuốc biểu mố. Phương pháp: Nghiên cứu mô tả hồi cứu. Kết quả: Thời gian nằm viện trung bình 10,3 ngày, tỷ lệ biến chứng sớm $8.3 \%$. Theo dõi $81,9 \%$ bệnh nhân: 361 bệnh nhân còn sống $(78,5 \%), 99$ bệnh nhân đã chết $(21,5 \%)$, thời gian sống sau mổ trung bình là 36,9 tháng. Tî lệ bệnh nhân sống sau mổ 1 năm, 3 năm và 5 năm tướng ứng 78,5\%,43,5\%, 22,4\%. Trong các loại tổn thương, u GIST khả năng sống sau mổ cao hởn so với u lympho. Có 87 bệnh nhân có điều trị bổ trợ sau mổ (chủ yếu là u lympho và u GIST) có thời gian sống sau mổ trung bình cao hơn so với nhóm không điểu trị bổ trợ. Kết luâan: Mặc dù chiếm tỷ lệ thấp hơn nhiều so ung thư biểu mô, nhưng các u này cũng có những biến chứng nặng mang tính chất cấp cứu có thể dẫn đến tử vong, do vậy việc đánh giá kết quả sau mổ là rất quan trọng để có cách thức điều trị và tiên lượng cho bệnh nhẩn.

Tư khóa: U không thuộc biểu mô ống tiêu hóa, đánh giá sau mổ, thời gian sống sau mổ

\section{SUMMARY \\ EVALUATE THE SURGERY RESULTS OF NON- EPITHELIAL CANCER OF GASTROINTESTINAL TRACT OPERATED AT VIET DUC UNIVERSITY HOSPITAL IN 10 YEAR}

Objective: Evaluate the surgery results of nonepithelial cancer of gastrointestinal tract (GI). Methods: retrospective study. Results: The average hospital stay was 10.3 days, the rate of early

${ }^{1}$ Bệnh viện Hữu nghi Việt Đức

Chị trách nhiêm chính: Phạm Gia Anh

Email: phamgiaanh@gmail.com

Ngày nhận bài: 19.11.2020

Ngày phản biện khoa học: 11.01.2021

Ngày duyệt bài: 20.01.2021
Phạm Gia Anh', Trịnh Hồng Sơn'

complications was $8.3 \%$. Follow up $81.9 \%$ of patients: 361 patients were still alive $(78.5 \%), 99$ patients died $(21.5 \%)$, the average survival time post surgery was 36.9 months. The rates of patients living after 1 year, 3 years and 5 years after surgery are $78.5 \%, 43.5 \%$, $22.4 \%$ respectively. Among the types of lesions, GIST tumors have higher postoperative survival than lymphoma. There were 87 patients with postoperative adjuvant treatment (mainly lymphoma and GIST tumors) had a higher mean postoperative survival time compared to the group without adjuvant treatment. Conclusion: Although non-epithelial tumors's prevalence rate is lower than adenocarcinoma, it also have serious complications of an emergency that can lead to death, therefore, it is very important to evaluate the outcomes after surgery for the treatment and prognosis of the patient.

Keywords: non-epithelial gastrointestinal tract tumors, postoperative evaluation, survival time

\section{I. ĐĂT VẤN ĐỀ}

Ung thư ống tiêu hóa (ÔTH) không thuộc biểu mô bao gồm nhóm u trung mô (Digestive Mesenchymal Tumors) và u lympho của ÔTH, chiếm tỉ lệ dưới $5 \%$ toàn bộ ung thư của ÔTH, có hơn 10 loại khác nhau bao gồm nhóm chiếm tỉ lệ ít hơn có hình ảnh mô bệnh học và tiêu chuẩn chẩn đoán giống u mô mềm ở các cơ quan khác như u mõ̃, u cơ trơn, u vỏ bao thần kinh, u mạch máu, u cơ vân... và nhóm khác chiếm phần lớn không đồng nhất gọi là u mô đệm ống tiêu hoá hay u mô đệm dạ dày ruột (GIST - GastroIntestinal Stromal Tumors) và u lympho [1],[2]. Trên thế giới và tại Việt Nam cũng đã có các công trình nghiên cứu về u ÔTH không thuộc biểu mô, tuy nhiên các tác giả thường nghiên cứu môtt loại tổn thương trên môt hoặc nhiều tạng mà chưa có nghiên cứu nào một 
cách tổng thể cũng như kết quả điều trị phẫu thuật của các loại u không thuộc biểu mô của toàn bộ ÔTH. Mặc dù chiếm tỷ lệ thấp hơn nhiều so ung thư biểu mô, nhưng các u này cũng có những biến chứng nặng mang tính chất cấp cứu có thể dẫn đến tử vong (như xuất huyết tiêu hóa, thủng ruột, tắc ruột, lồng ruột...), do vậy viêcc hiểu được các phương pháp phẫu thuật và kết quả sau mổ là rất quan trọng để có cách thức điều trị và tiên lượng cho bệnh nhân. Chính vì vậy chúng tôi thực hiện nghiên cứu này nhằm muc tiêu: "Đánh giá kết quả điều tri phầu thuât của ung thưống tiêu hóa không thuộc biểu mô".

\section{II. ĐốI TƯỢNG VÀ PHƯƠNG PHÁP NGHIÊN CỨU}

2.1. Địa điểm, thời gian nghiên cứu: Bệnh viện Hữu nghị Việt Đức trong thời gian 10 năm từ 1/2009 đến 4/2019.

2.2. Đối tượng nghiên cứu: Những bệnh nhân có khối u mõ̃ ác tính tại ống tiêu hóa được chẩn đoán xác định bằng giải phẫu bệnh, đã phẫu thuật cấp cứu hoặc mố phiên tại Bệnh viện hữu nghị Việt Đức.

\subsection{Phương pháp nghiên cứu}

2.3.1. Thiết kế nghiên cứu: Nghiên cứu hồi cứu theo phương pháp mô tả

2.3.2. Cỡ mầu: Tất cả các các bệnh nhân đủ tiêu chuẩn nghiên cứu trong thời gian 10 năm từ 1/2009 đến 4/2019

\subsubsection{Phương pháp thu thập số liêuu}

Bước 1: Lấy toàn bộ kết quả giải phẫu bệnh tại khoa giải phẫu bệnh trong 10 năm từ $1 / 2009$ đến 4/2019

Bước 2: Trong các kết quả này, lọc ra những chẩn đoán u mõ ác tính của thực quản, dạ dày, tá tràng, ruột non, đại tràng, trực tràng và hậu môn.

Bước 3: - Từ kết quá thu được ở bước 2, lập danh sách tên, tuổi, chẩn đoán lâm sàng, khoa phòng gửi bệnh phẩm và ngày đọc tiêu bản giải phẫu bệnh.

- Từ đó tra được ngày ra vào viện của từng bệnh nhân để tìm hồ sơ bệnh án.

- Kiểm tra hồ sơ đầy đủ mới lấy vào số liệu.

2.3.4. Tiêu chuẩn lựa chọn bệnh nhân: Mỗi bệnh nhân được lựa chọn vào nghiên cứu có đầy đủ các tiêu chuẩn sau:

- Kết quả giải phẫu bệnh chẩn đoán xác định là u mõ ác tính ông tiêu hóa

- Cả hai giới nam và nữ, mọi lứa tuổi.

- Được điều trị phẫu thuật.

- Có đầy đủ hồ sơ bệnh án với lâm sàng và kết quả cận lâm sàng, biên bản phẫu thuật, giấy kết quả giải phẫu bệnh.

\subsection{Chỉ tiêu nghiên cứu}

Kết quả gân: - Bệnh nhân ổn định: sau mổ diễn biến bình thường ra viện

- Có biến chứng sau mố: theo ghi nhận trong hồ sơ bệnh án: Nhiễm trùng vết mổ: khi phải tách, cắt chỉ sớm, dùng kháng sinh. Áp xe tồn dư, viêm phúc mạc, tràn dịch màng phổi, viêm phổi, nhiễm trùng tiết niệu, chảy máu sau mổ.

- Chết, nặng xin về: trong vòng 30 ngày kể từ khi mổ.

\section{Kết quả xa:}

- Sau mổ bệnh nhân có được điều trị hỗ trợ không: hóa chất, xạ trị, điều trị đích, miễn dịch...

- Thời gian sống sau mổ (tháng): tình trạng hiện tại của bệnh nhân (sống, chết, hay mất tin) của các nhóm giải phẫu bệnh để tính thời gian sống theo phương pháp Kaplan-Meier.

2.5. Phương pháp xử lý số liệu: Phần mềm SPSS 22.0

\section{KẾT QUẢ NGHIÊN CứU}

3.1. Kết quả chung và biến chứng sau mổ

Bảng 3.1. Kêt quả chung sau mố

\begin{tabular}{|c|c|c|c|c|}
\hline Loại u & $\begin{array}{c}\text { Tốt, ra } \\
\text { viện n } \\
(\mathbf{\%})\end{array}$ & $\begin{array}{c}\text { Năng, } \\
\text { xin về } \\
\text { n (\%) }\end{array}$ & $\begin{array}{c}\text { Tử vong } \\
\mathbf{n} \mathbf{( \% )}\end{array}$ & Tổng \\
\hline U cơ trơn & $5(0,9)$ & $0(0)$ & $0(0)$ & 5 \\
\hline U lympho & $132(24,3$ & $13(90,9)$ & $1(100)$ & 145 \\
\hline U mỡ & $7(1,3)$ & $0(0)$ & $0(0)$ & 7 \\
\hline U cơ vân & $1(0,2)$ & $0(0)$ & $0(0)$ & 1 \\
\hline U hắc tố & $5(0,9)$ & $0(0)$ & $0(0)$ & 5 \\
\hline U mạch & $1(0,2)$ & $0(0)$ & $0(0)$ & 1 \\
\hline U GIST & $392(72,2$ & $1(9,1)$ & $0(0)$ & 393 \\
\hline Tổng & $\mathbf{5 4 3}$ & $\mathbf{1 4}$ & $\mathbf{1}$ & $\mathbf{5 5 7}$ \\
\hline
\end{tabular}

Nhận xét: - Đa số bệnh nhân có kết quả tốt ra viện với tỉ lệ $97,5 \%$.

- 13/15 ca tử vong/ nặng xin về là u lympho, trong đó 7 ca mổ cấp cứu.

\section{Bảng 3.2. Biến chứng sớm sau mổ}

\begin{tabular}{|c|c|c|}
\hline Các loại biến chứng & $\begin{array}{c}\text { Số lướng } \\
(\mathbf{n})\end{array}$ & $\begin{array}{c}\text { Tỷ lệ } \\
\mathbf{( \% )}\end{array}$ \\
\hline Không có biến chứng & 514 & 92,3 \\
\hline Chảy máu & 5 & 0,9 \\
\hline Rò tiêu hóa & 3 & 0,5 \\
\hline Viêm Phối & 6 & 1,1 \\
\hline Tràn dịch màng phối & 0 & 0 \\
\hline Ap xe tồn dư & 2 & 0,4 \\
\hline Nhiêm trùng vết mố & 14 & 2,5 \\
\hline Sốt & 12 & 2,2 \\
\hline Bí đái & 0 & 0 \\
\hline Viêm phúc mạc & 1 & 0,2 \\
\hline Tống & $\mathbf{5 5 7}$ & $\mathbf{1 0 0}$ \\
\hline
\end{tabular}

Nhận xét: - 1 trường hợp u lympho VFM sau mổ rồi nặng xin về.

- 5 ca chảy máu sau mổ đều là GIST. 
- 3 ca rò tiêu hóa trong đó 1 u GIST và 2 u lympho.

\subsection{Kết quả xa}

Bảng 3.3. Kêt quả xa sau mố Số lượng (n) Tỷ lệ (\%)

\begin{tabular}{|c|c|c|}
\hline Chết & 99 & 21,5 \\
\hline Sống & 361 & 78,5 \\
\hline $\begin{array}{c}\text { Số bệnh nhân } \\
\text { liên lạc được }\end{array}$ & $\mathbf{4 6 0}$ & $\mathbf{1 0 0}$ \\
\hline
\end{tabular}

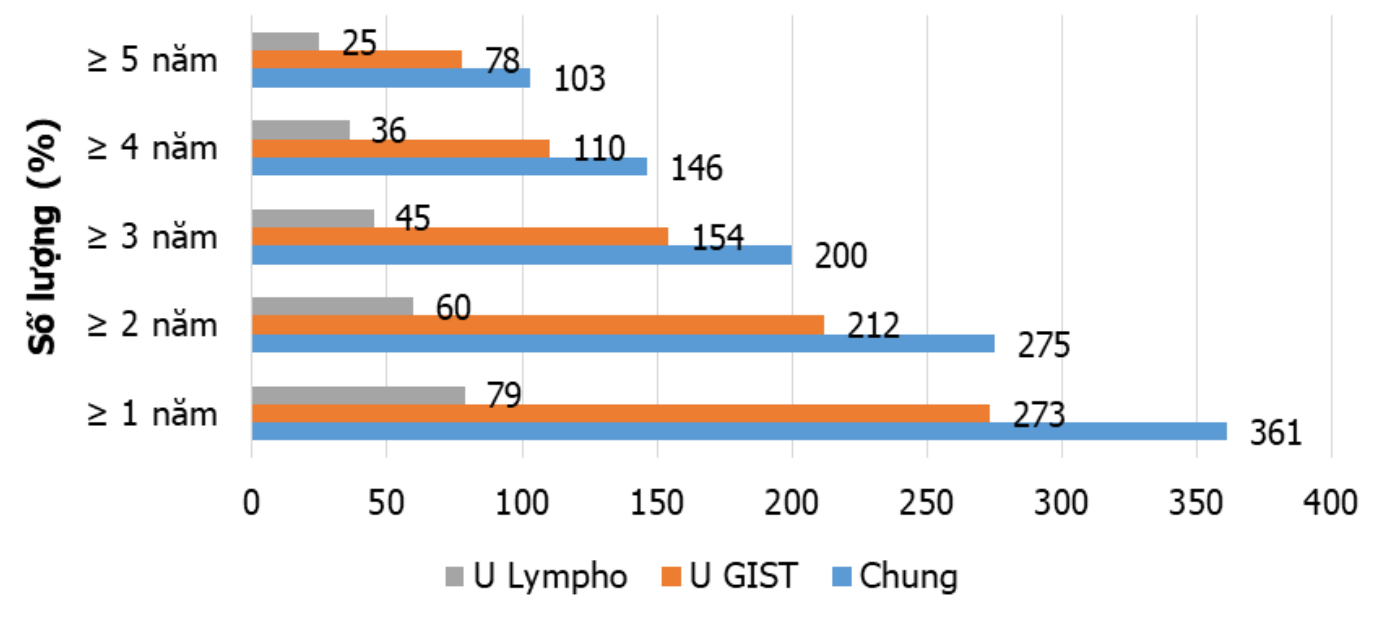

Biêu đồ 3.1. Thời gian sống thêm sau mổ theo năm

Bảng 3.4. Thời gian sống, tỉ lệ sống - chết và điều trị hố trợ sau mổ

\begin{tabular}{|c|c|c|c|c|c|}
\hline Loại u & $\begin{array}{l}\text { Số BN liên } \\
\text { lạc n (\%) }\end{array}$ & $\begin{array}{l}\text { Sống } \\
\text { n (\%) }\end{array}$ & $\begin{array}{l}\text { Chết } \\
\text { n (\%) }\end{array}$ & $\begin{array}{c}\text { Thơoi gian sống thêm } \\
\text { trung bình (tháng) } \\
\text { Min - Max }\end{array}$ & $\begin{array}{l}\text { Điều trị hô } \\
\text { trợ sau mổ } \\
\text { n (\%) }\end{array}$ \\
\hline U cơ trơn & $5(1,1)$ & $4(80)$ & $1(20)$ & $19,6 \pm 7,3(13-26)$ & $1(20)$ \\
\hline U lympho & $117(25,4)$ & $72(61,5)$ & $45(38,5)$ & $34,1 \pm 31,5(0-121,1)$ & $64(56,6)$ \\
\hline U mõ & & & $3(50)$ & $31 \pm 29,5(2-88)$ & $2(33,3)$ \\
\hline U cơ vân & $1(0,2)$ & $1(100)$ & $0(0)$ & $17 \pm 0(17-17)$ & $1(100)$ \\
\hline U hắc tố & $4(0,9)$ & $0(0)$ & $4(100)$ & $22,6 \pm 14,2(3,6-36)$ & $0(0)$ \\
\hline $\mathrm{Un}$ & & 0 & & $1 \pm 0(1-1)$ & $0(0)$ \\
\hline$U G$ & & 281( & & $1 \pm 26,7(0-109,2)$ & 19 \\
\hline Tống(\%) & $460(100)$ & $361(78,5)$ & $99(21,5)$ & $36,9 \pm 28,0(0-121,1)$ & $87(19,1)$ \\
\hline
\end{tabular}

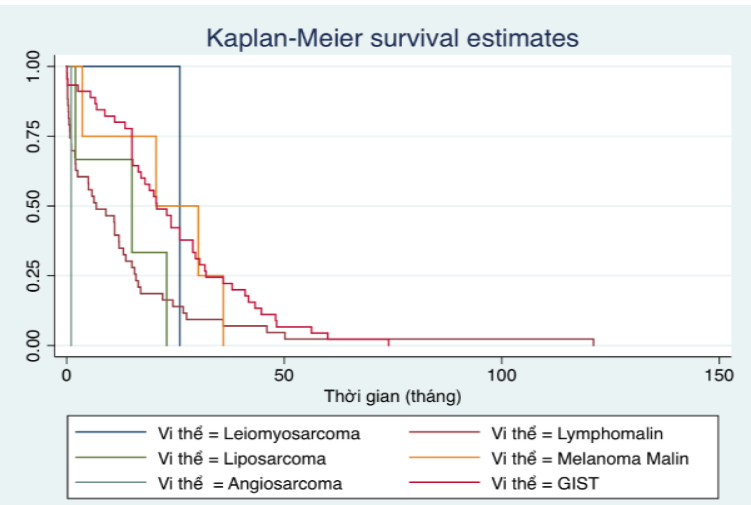

Biểu đồ 3.2. Thời gian sống thêm sau mổ của mối loai u (tháng)

Nhân xét: - Theo dỗi được 460 trường hợp

- Thời gian sống thêm trung bình: $36,9 \pm 28$ (tháng).

- Ngắn nhất: 1 ngày. Lâu nhất 121,1 tháng.
- Theo dõi dài nhất được 132 tháng, ngắn nhất là 9 tháng

\section{BÀN LUẬN}

4.1. Kết quả chung sau mổ. Đa số bênh nhân có kết quả tốt ra viện với tỉ lệ $97,5 \%$, còn lại 15 trường hợp với 14 ca nặng xin về (trong đó 13 ca là u lympho với 4 ca tổn thương tại dạ dày, $4 \mathrm{ca}$ ở ruột non, 1 u GIST) và 1 ca tử vong sau mổ là u lympho, trong 15 ca này có $7 \mathrm{ca}$ phải mổ cấp cứu, điều này cho thây những biến chứng nặng của u lympho hoặc tổn thương ở giai đoạn muộn lan tỏa xâm lấn rộng của u lympho sẽ nặng như thế nào.

Thời gian nằm viện trung bình 10,3 ngày, lâu nhất là 52 ngày, giống như kết quả của Nguyễn Thành Khiêm 10,5 ngày [3] và dài hơn so với 9,7 ngày của Bùi Trung Nghĩa [4]. Đáng chú ý có 76 ca $(13,6 \%)$ nằm điều trị trên 2 tuân (14 ngày) 
trong đó 46 ca GIST, 22 ca là u lympho, $2 / 5 \mathrm{ca} \mathrm{u}$ hắc tố ác tính, $2 / 5 \mathrm{ca}$ u cơ vân ác tính, $1 \mathrm{ca}$ u mạch ác tính và $2 / 7$ ca u mõ ác tính, như vậy tính tỉ lệ số ca nằm dài ngày thì u GIST là ít nhất so với các loại u còn lại.

4.2. Biến chứng sớm sau mổ. $543 / 557 \mathrm{BN}$ (chiếm 97,5\%) diễn biến hậu phẫu thuận lợi và ra viện. Tỷ lệ biến chứng sớm khá thấp với 43/557 BN (chiếm 7,7\%). Các biến chứng như nhiễm trùng tiết niệu, nhiễm trùng vết mổ hay viêm phổi thường nhẹ và được điều trị khỏi hoàn toàn trước khi ra viên. Có 1 trường hợp u lympho sau mổ viêm phúc mạc rồi nặng xin về, $5 \mathrm{ca}$ chảy máu sau mổ đều là GIST nhưng bệnh nhân đều được điều trị ổn và ra viên, 3 ca rò tiêu hóa là 1 u GIST và 2 u lympho (trong đó 1 ca năng xin về và 1 ca mổ cấp cứu do VFM do thủng ruột non). Cho thấy các biến chứng nặng sau mổ xảy ra ở u lympho nhiều hơn, tỉ lệ biến chứng trong nghiên cứu về u lympho của Nguyễn Thành Khiêm về VFM do bục miệng nối là $4,1 \%$ và rò tiêu hóa là $2 \%$, không có biến chứng chảy máu [3], biến chứng nặng trong 84 ca GIST của Bùi Trung Nghĩa là 2 trường hợp bị suy đa tạng sau mổ chiếm 2,4\% [4].

4.3. Kết quả xa. Chúng tôi liên hệ được 460/557 bệnh nhân $(81,9 \%)$ trong số nghiển cứu với thời gian theo dõi được dài nhất 132 tháng, ngắn nhất 9 tháng, cho kết quả như sau:

- 361 bệnh nhân còn sống (78,5\%), 99 bệnh nhân đã chết $(21,5 \%)$

- Thời gian sống sau mổ lâu nhất 121,1 tháng và ngắn nhất là 1 ngày

- Thời gian sống sau mổ trung bình là: 36,9 \pm 28 tháng

So sánh với ung thư biểu mô tuyến ÔTH, thời gian sống trung bình của các loại ung thư không biểu mô trong nghiên cứu là $36,9 \%$ cao hơn so nghiên cứu của Trịnh Hồng Sơn về ung thư biểu mô tuyến da dày là 32 tháng [5] với khả năng sống thêm sau 1 năm là $73,22 \%$, sau 2 năm là $65,32 \%$, sau 3 năm là $56,08 \%$, sau 4 năm là $52,34 \%$. Đỗ Đức Vân nghiên cứu kết quả xa sau mổ ung thư biểu mô dạ dày cho thấy các tỷ lệ đó lần lượt là: $72 \%, 49 \%, 29 \%$, và khả năng sống thêm sau 4 năm là $22 \%[6]$, kết quả của chúng tôi tương ứng là $78,5 \%, 59,8 \%, 43,5 \%$ và $31,7 \%$. Thời gian sống trung bình của nhóm u mô liên kết dạ dày của tác giả Nguyễn Ngọc Hùng cao hơn trong nghiên cứu này $(48,48$ tháng), khả năng sống thêm sau 1 năm là $73,91 \%$, sau 2 năm là $62,91 \%$. Các nghiên cứu trên thế giới: với ung thư thực quản được tỉ lệ sống trên 5 năm với biểu mô vảy là $22,8 \%$, biểu mô tuyến 20,2\% (2016, Brazil, 549 bệnh nhân; với ung thư biểu mô tuyến dạ dày là $68,2 \%$ (2017, Nhật Bản, nghiên cứu dữ liệu trên 118367 bệnh nhân), của ruột non là $34,9 \%$ và đại tràng là 51,5\% (2016, Mỹ், 2123 ca ung thư biểu mô tuyến ruột non và 248862 ca ung thư biểu mô tuyến đại tràng) [7].

\section{KẾT LUẬN}

- Đa số bệnh nhân có kết quả tốt ra viện với tỉ lệ 97,5\%.

- Thời gian nằm viện trung bình 10,3 ngày, lâu nhất là 52 ngày. Tỷ lệ biến chứng sớm khá thấp với 7 / 84 BN (chiếm 8.3\%).

- Theo dõi liên hệ được 460/557 bệnh nhân $(81,9 \%)$, gian theo dõ̃i được dài nhất 132 tháng, ngắn nhất 9 tháng: 361 bệnh nhân còn sông (78,5\%), 99 bệnh nhân đã chết $(21,5 \%)$, thời gian sống sau mổ lâu nhất 121 tháng và ngắn nhất là 1 ngày, thời gian sống sau mổ trung bình là 36,9 tháng. Tỉ lệ bệnh nhân sống sau mổ 1 năm, 3 năm và 5 năm tương ứng 78,5\%, 43,5\%, $22,4 \%$.

- Trong các loại tổn thương, u GIST khả năng sống sau mổ cao hơn so với u lympho.

- Có 87 bệnh nhân có điều trị bổ trợ sau mổ (chủ yếu là u lympho và u GIST) có thời gian sống sau mổ trung bình cao hơn so với nhóm không điều trị bổ trợ.

\section{TÀI LIẸU THAM KHẢO}

1. I. D. Nagtegaal et al (2020), "The 2019 WHO classification of tumours of the digestive system", Histopathology, 76(2), p. 182-188.

2. Fred T. Bosman và cộng sự (2010), "WHO Classification of Tumours of the Digestive System", 4 th ed. World health organization classification of tumours, ed. Fred T. Bosman, Elaine S. Jaffe, Sunil R. Lakhani, \& Hiroko OhgakiIARC, Lyon

3. Nguyển Thành Khiêm (2011), "Đặc điểm lâm sàng, cận lâm sàng của u lympho nguyên phát ống tiêu hóa được phẩu thuật tại bệnh viện Việt Đức"', Luận văn tốt nghiệp nôi trú, Đaai học y Hà Nội, HN.'

4. Bừi Trung Nghĩa (2011), "Đánh giá đặc đđiểm lâm sàng, cận lâm sàng và kêt quả điều trị phẫu thuật u mô đệm đường tiêu hóa (GIST) tại bệnh viền Việt Đức từ tháng 01/2005 đến 12/2010", Luận văn tốt nghiệp nội trú, Đại học y Hà Nội, Hà Nội.

5. Trịnh Hống Sớn (2001), "Nghiên cứu nao vét hạch trong điều trị ung thư dạ dày", Luận án tiến sỹ y hoc.

6. Đố Đức Vân (1993), "Điều trị phẫu thuật ung thư da dày tại bệnh viện Việt Đức (1970-1992)", Y học Việt Nam, 7, tr. 45-50.

7. J. I. Young et al (2016), "Treatment and Survival of Small-bowel Adenocarcinoma in the United States: A Comparison With Colon Cancer", Dis Colon Rectum, 59(4), p. 306-315. 